\title{
Effect of customized near addition lenses on transient myopia induced by near-work
}

This article was published in the following Dove Press journal:

Clinical Optometry

19 April 2010

Number of times this article has been viewed

Li Nan'

\section{Kenneth Seger ${ }^{2}$ \\ Melanie Crandall ${ }^{2}$ \\ Bai-Chuan Jiang ${ }^{2}$}

'Clinical College of Ophthalmology, Tianjin Medical University, Tianjin Eye Hospital, Tianjin, China; ${ }^{2}$ College of Optometry, Nova Southeastern University, Fort Lauderdale, Florida, USA
Correspondence: Bai-Chuan Jiang College of Optometry, Nova Southeastern University 3200 S. University Drive, Fort Lauderdale, FL 33328, USA

Email bjiang@nova.edu
Purpose: To verify whether optimal near add power can reduce near-work induced transient myopia (NITM).

Methods: Eighteen subjects including nine progressive myopes (PMs) and nine stable myopes (SMs) were involved in this study. We measured the accommodative error and the near phoria at $40 \mathrm{~cm}$ under fully corrected conditions for each subject. These findings were then used to determine optimal near-add power for each subject based on formulae derived from a previous study. Under both with and without near-add conditions, NITM was obtained by comparing the refractions immediately before and after performing continuous computer work at $40 \mathrm{~cm}$ for an hour. The refraction was determined by a COAS aberrometer.

Results: Using customized near-addition lenses (C-ADD) we found significantly decreased retinal defocus from $0.49 \pm 0.12(\mathrm{SD}) \mathrm{D}$ to $0.08 \pm 0.11 \mathrm{D}$. The near phoria showed a significant exophoric shift from $-1.84 \pm 1.95$ prism diopter $(\mathrm{pd})$ to $-5.37 \pm 1.63 \mathrm{pd}$, but was still in the normal range. We also found that the differences in NITM between the two groups and between the two conditions (ie, with and without C-ADD) were both significant. Further comparisons indicated that the NITM in the SM group was significantly reduced after using C-ADD; in the PM group the reduction of NITM was not significant.

Conclusions: The results suggest that C-ADD balances the load of accommodation and vergence, significantly decreasing retinal blur during the near-work, and may be able to reduce the NITM.

Keywords: myopia, near-addition lenses, accommodation, near phoria, transient myopia

\section{Introduction}

Myopia is a worldwide public health problem. Both family history and amount of near-work have been identified as risk factors for the development and progression of myopia in previous studies. ${ }^{1-5}$ Some recent studies have suggested that the progression of myopia in school children might not be associated with near-work and/or reading, but negatively related to the time spent doing sports and outdoor activities. ${ }^{6-9}$ However, these findings have not been confirmed in young adults. The difference between school children and young adults is that childhood myopia progression generally ceases between 15 to 17 years of age, at about the same time as the cessation of general body growth. ${ }^{10}$ Therefore, genetic factors may have less influence in the development of myopia among young adults. For example, Bullimore et al showed in SPAN (Study of Progression of Adult Nearsightedness) that, among young adult subjects, twice the number of late-onset myopes $(32.1 \%$ ) reported no parental history of myopia compared with early-onset myopes $(16.6 \%) .{ }^{11}$ 
Looking at environmental factors, studies using animal models and humans suggest that hyperopic retinal defocus could cause axial elongation leading to development of myopia. ${ }^{12-14}$ Numerous researchers have focused on the accommodative mechanism because inaccurate accommodation is closely related to a blurred image on the retina. It has been found that myopes tend to have a larger lag of accommodation. ${ }^{15-17}$ Recent studies in children suggested that the increase in accommodative lag did not occur before or during the onset of myopia. ${ }^{18,19}$ For adults, McBrien and Adams ${ }^{20}$ conducted a longitudinal study with subjects who were clinical microscopists. They found that adult-onset and/or adult-progression of myopia was related to vitreous chamber elongation. We feel that the retinal defocus has not been excluded from the risk factors for development of myopia, especially for late-onset myopia.

In contrast with lag of accommodation, which represents an accommodative response error to a near target, nearwork induced transient myopia (NITM) refers to a small, transient, near shift in the far point of the eye after a period of sustained near-work. ${ }^{21-24}$ Recent research results showed that myopes had larger and longer NITM compared with emmetropes. ${ }^{25,26}$ In addition, it has been demonstrated that the NITM was additive in myopic subjects. ${ }^{24}$ Following this line of reasoning, it is speculated that accumulation of NITM caused by repeated or prolonged near-work might contribute to the progression of permanent myopia.

Based on the rationale that when using near-addition lenses the lag of accommodation for the near target would be reduced, numerous studies concentrated on using plus lenses or progressive near-addition lenses (PALs) to control progression of childhood myopia. However, the results from these studies were inconsistent. Some of these studies showed that there was no significant delay in myopia progression. ${ }^{27-29}$ Gwiazda et al found the reduction of myopic progression was statistically significant, but but not clinically significant. ${ }^{30}$ Leung and Brown reported the use of both $+1.50 \mathrm{D}$ and $+2.00 \mathrm{D}$ PALs compared with single vision lenses (SVLs) showed fewer myopic changes in a two-year longitudinal study. ${ }^{31}$ Considering that a big lag of accommodation tends to be associated with esophoria in myopia, studies of near-addition lenses further analyzed subjects' near phoria and lag of accommodation. ${ }^{32}$ The results suggested that both bifocal and PALs worked well for children with near esophoria and a large lag of accommodation, but they were not really helpful in controlling myopia progression in subjects who had near orthophoria, exophoria, or a small lag of accommodation..$^{33-36}$
To investigate accommodative performance when the subject wore near-addition lenses, Rosenfield and $\mathrm{Carrel}^{37}$ compared binocular accommodative responses (ARs) to a $40 \mathrm{~cm}$ stimulus when the subject was viewing through his distance correction or his distance correction plus +0.75 , $+1.50,+2.00$, or $+2.50 \mathrm{D}$ near-addition lens, respectively. They found that the appropriate plus lens which would result in no error of accommodation (no lead or lag) was determined by the subject's initial accommodative error. This suggested that individuals might need customized near-addition lenses (C-ADD). Jiang et $\mathrm{al}^{38}$ reported that the subject's near phoria shifted to a more exphoric direction when using a $+2 \mathrm{D}$ near-add. In addition, the subject's AR to a $40 \mathrm{~cm}$ target was significantly higher when viewing binocularly compared with monocular viewing. This result suggested that vergence accommodation contributed to the $\mathrm{AR}$ under binocular viewing conditions. By evaluating accommodative responses, phorias, and fixation disparities in 30 young adults when they viewed through various addition lenses at three working distances $(50 \mathrm{~cm}, 40 \mathrm{~cm}$, and $30 \mathrm{~cm}$ ), Jiang et a ${ }^{39}$ calculated the optimal power values of near-addition lenses associated with least accommodative error and the optimal powers associated with -3.0 prism diopter (pd) exophoria at near (ie, the mid-point of Morgan's norm) for the three working distances, respectively. In addition, they derived two equations which could be used to find the best power of near-addition lenses based on the individual's initial accommodative error (AE) and near phoria values.

To verify the effectiveness of the customized near-addition powers derived from the previous study, ${ }^{39}$ we undertook the present study comparing the difference in NITM caused by a near-reading task under the conditions of with and without customized near-additions.

\section{Methods}

Eighteen optometry students from Nova Southeastern University participated in this study. Their mean age was $25.2 \pm 4.63$ (SD) years, ranging from 21 to 42 , including five males and 13 females. Full subjective refraction and binocular vision evaluation was performed before the experiment by the first author for all subjects. Monocular visual acuity with the individual's best correction was equal to or better than 20/20 for each subject. All subjects were myopic and their refractive errors were equal to or greater than $-1.00 \mathrm{D}$, and astigmatism was no more than $1.00 \mathrm{D}$. They all had normal binocular function. None of them had a history of ocular disease or surgery. 
The subjects were divided into two groups: One made up of nine stable myopes (SMs) whose spherical and astigmatic component of the refractive error had changed less than $0.50 \mathrm{D}$ over previous two years; the other group of nine progressive myopes (PMs) whose spherical and astigmatic component of the refractive error had increased equal to or more than $0.50 \mathrm{D}$ over previous two years. Information on the changes in each subject's refractive error was obtained from his/her medical file. The criterion used to assign the subjects to the SM group and the PM group was similar to that used by McBrien and Adams. ${ }^{20}$ The mean refractive error was $-4.11 \pm 1.35 \mathrm{D}$ for SMs and $-4.20 \pm 0.81 \mathrm{D}$ for PMs. Consent forms were obtained from each subject after the nature and possible consequences of the experiment were explained. The research followed the tenets of the Declaration of Helsinki and was approved by the Nova Southeastern University's Committee for the Protection of Human Subjects.

We measured the subject's AR when a target was at $40 \mathrm{~cm}$ (ie, AS = 2.50 D) using a Canon R-1 auto-refractor (Canon Europe NV, Amsterdam, The Netherlands). The subjects' refractive errors were corrected with contact lenses. The accommodative target was a dark Maltese cross $\left(7 \times 7 \mathrm{~mm}^{2}\right)$ displayed on a slide $\left(24 \times 35 \mathrm{~mm}^{2}\right)$ mounted in front of a tungsten illuminator. The luminance of the target was $250 \mathrm{~cd} / \mathrm{m}^{2}$. The target was aligned with the subject's right eye under binocular viewing conditions, and the AR of this eye was measured by the Canon R-1 auto-refractor. Each AR value was calculated as the average spherical equivalent power (ie, sphere power $+1 / 2$ cylinder power) from 10 Canon $\mathrm{R}-1$ readings. Because the Canon R-1 was designed to provide the power needed for spectacle correction, we converted all readings to the power at the subject's corneal plane. Then, the subject's initial accommodative response error (AE) was calculated according the formula $\mathrm{AE}=\mathrm{AS}-\mathrm{AR}$.

We measured the initial phoria at $40 \mathrm{~cm}$ by the von Graefe technique. It was performed behind a phoropter under 450 lux room illumination. The targets were 20/20 reduced Snellen equivalent letters. Binocular fusion was broken by adding a $20 \mathrm{pd}$ of base-in (BI) prism in front of the subject's right eye and a 6 pd of base-down (BD) prism in front of the left eye. When the subject concentrated on the stationary upper letters, the BI prism was slowly reduced until the subject reported that the two squares of letters were perfectly aligned vertically. The reading of the horizontal prism was recorded. This procedure was repeated three times, and the average was recorded as the amount of near phoria.

In the study by Jiang et a ${ }^{39}$ high correlations were found between the initial $\mathrm{AE}$ and the best power of the near-addition lenses and between the initial near phoria and the best power of the near-addition lenses. The optimal power means that it could lead to zero AE or -3 pd phoria when the subject views a target at $40 \mathrm{~cm}$. Therefore, using an individual's initial AE and phoria values, we could calculate the customized power of addition lens based on the following equations derived in the study by Jiang et al:

1. Customized near-add power $1=($ initial AE -0.134$) / 0.238$

2. Customized near-add power $2=$ (initial phoria + 2.959)/2.770

When the powers of the customized addition lens calculated from the two equations were unequal for the same subject, we took the average of the two values and rounded to the nearest $0.25 \mathrm{D}$ to determine the power of the subject's near-addition lenses.

To verify the effect of customized near-add power on the accommodative and vergence responses, we measured $\mathrm{AE}$ and the phoria at $40 \mathrm{~cm}$ when the subject was looking through the C-ADD. The measurement procedure was the same as described above. The near-addition lenses were inserted in lens wells mounted on the forehead rest of the Canon R-1 at a vertex distance of $12 \mathrm{~mm}$ from the subject's eyes.

After the $\mathrm{AE}$ and near phoria were measured with the C-ADD, the subject was asked to perform a near visual task, which was one hour of computer work at $40 \mathrm{~cm}$ when the subject wore his/her full correction either with or without the C-ADD. By adjusting the seat and computer monitor, the distance from the subjects' eye to the monitor (luminance $=$ $36 \mathrm{~cd} / \mathrm{m}^{2}$ ) was set to $40 \mathrm{~cm}$, and the eyes were at the same height at the center of the monitor.

NITM was obtained by comparing the subject's refractions as determined by a COAS aberrometer (WaveFront Science, Inc., Albuquerque, New Mexico) immediately before and after performing the near task mentioned above. This was done on two separate occasions with and without the C-ADD, in a randomized order. During the NITM measurement, the subject was instructed to look at the Maltese cross $\left(163 \times 83 \mathrm{~mm}^{2}\right.$, average luminance $\left.250 \mathrm{~cd} / \mathrm{m}^{2}\right)$ displayed on a DVD player $5 \mathrm{~m}$ away by his/her left eye and a normal fixation target inside the aberrometer by the right eye. The DVD player was adjusted to align the Maltese cross with the normal fixation target. Ten frames (one set of continuous capture) of wavefront measurements on the right eye were taken. For post-NITM, the measurements were finished within 30 seconds after the near task. The spherocylindrical powers with a $4 \mathrm{~mm}$ pupil were exported and calculated for NITM. The accuracy of the COAS aberrometer for measurement of refractive errors has been proven to be 
similar to those of the autorefractor and subjective refraction in our laboratory ${ }^{40}$ and those of others. ${ }^{41-43}$

\section{Statistic analysis}

SPSS 13.0 statistics software was used to analyze the results. In the repeated measures ANOVA, the dependent variables were the AE, near phoria, and NITM, respectively, in each analysis; and the two myopia groups (SM and PM) and the two lens conditions (with and without customized near-add) were the two independent variables. When a significant difference was found by ANOVA, the post hoc Bonferroni t-test, which is a method of controlling the level of significance when computing multiple t-tests, was applied to test the difference between the two groups or the two lens conditions.

\section{Results}

\section{Initial $A E$ and $A E$ with customized near-addition lenses}

The individual's power of C-ADD was calculated based on the average results from equations 1 and 2. For the SM and PM groups, the average powers were $0.92 \pm 0.25 \mathrm{D}$ and $1.08 \pm 0.43 \mathrm{D}$, respectively. There was no significant difference between the two average values $(\mathrm{t}=0.826$, $P=0.42$ ). Although each subject's C-ADD value was the average obtained from his/her initial $\mathrm{AE}$ and phoria values, $\mathrm{C}$-ADD values for all 18 subjects were still correlated with their initial AEs $(\mathrm{R}=0.48, P=0.045)$ and initial phorias $(\mathrm{R}=0.69$, $P=0.0015)$, but the C-ADD values had no correlation with their refractive errors $(\mathrm{R}=0.026, P=0.92)$.

The average initial AEs (ie, without the customized near-addition lenses) were $0.46 \pm 0.08$ (SD) D and $0.52 \pm 0.14$ $\mathrm{D}$ for SMs and PMs, respectively. With the C-ADD, the average AEs became $0.05 \pm 0.11 \mathrm{D}(\mathrm{SMs})$ and $0.09 \pm 0.12$ $\mathrm{D}$ (PMs). The AEs in both groups were significantly affected by the C-ADD (SM or PM: $P<0.001$ ). The individual AE values of the two groups with and without $C$-ADD are plotted in Figure 1. The difference in the initial AE and the AE with $\mathrm{C}-\mathrm{ADD}$ between the SMs and PMs were not significant.

\section{Initial phoria and phoria with customized near-addition lenses}

The average initial near phorias (ie, without the C-ADD) were $-1.93 \pm 1.38(\mathrm{SD}) \mathrm{pd}$ and $-1.70 \pm 2.47 \mathrm{pd}$ for SMs and PMs, respectively. With the C-ADD, the average near phorias became $-5.26 \pm 1.15 \mathrm{pd}(\mathrm{SMs})$ and $-5.48 \pm 2.07 \mathrm{pd}(\mathrm{PMs})$, which showed a significant exophoric shift (SM: $P=0.003$; PM: $P=0.001)$. The individual near phoria values of the two groups with and without C-ADD are plotted in Figure 2.
The difference in the initial near phoria and the near phoria with C-ADD between the SMs and PMs was not significant.

\section{Near-work induced transient myopia}

The NITM data are presented in Figure 3. The difference in NITM between the two groups $(P=0.009)$ and between the two conditions (ie, with and without C-ADD) $(P=0.001)$ were both significant. There was no interaction between the group and the $\mathrm{C}$-ADD condition $(P=0.40)$. Further comparisons indicated that the NITM in the SM group was significantly reduced from $0.16 \pm 0.06 \mathrm{D}$ to $0.02 \pm 0.11 \mathrm{D}$ after using C-ADD $(P=0.016)$. In the PM group, NITM was reduced from $0.21 \pm 0.06 \mathrm{D}$ to $0.13 \pm 0.10 \mathrm{D}$; however, the decrease was not statistically significant. In addition, in conditions of with C-ADD and without C-ADD, the differences in the NITM values between PMs and SMs were not significant.
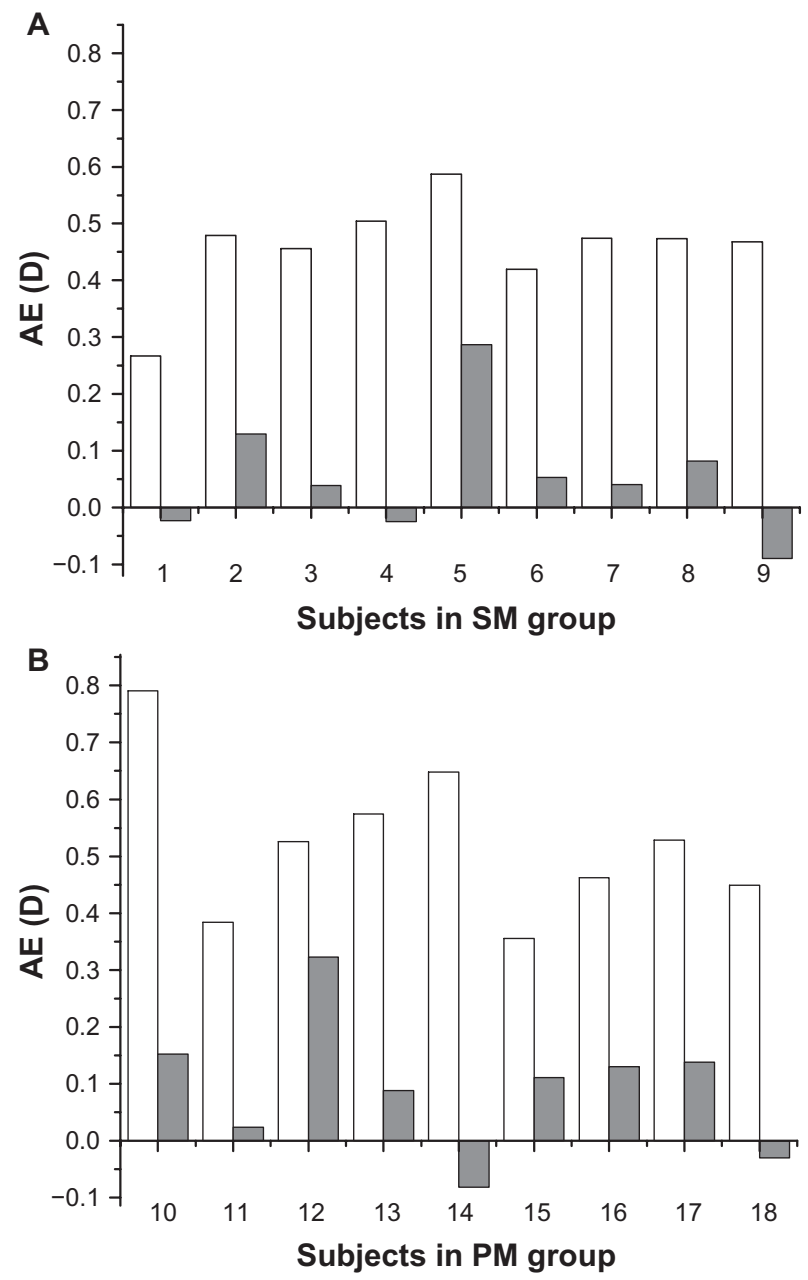

Figure I The initial AE (white bars) and the AE with C-ADD (dark bars) for each subject: A) subjects in SM group, B) subjects in PM group. In the $y$-axis, + sign represents the lag of accommodation; - sign represents the lead of accommodation.

Abbreviations: AE, accommodative response error; C-ADD, customized near addition lenses; PM, progressive myopia; SM, stable myopia. 

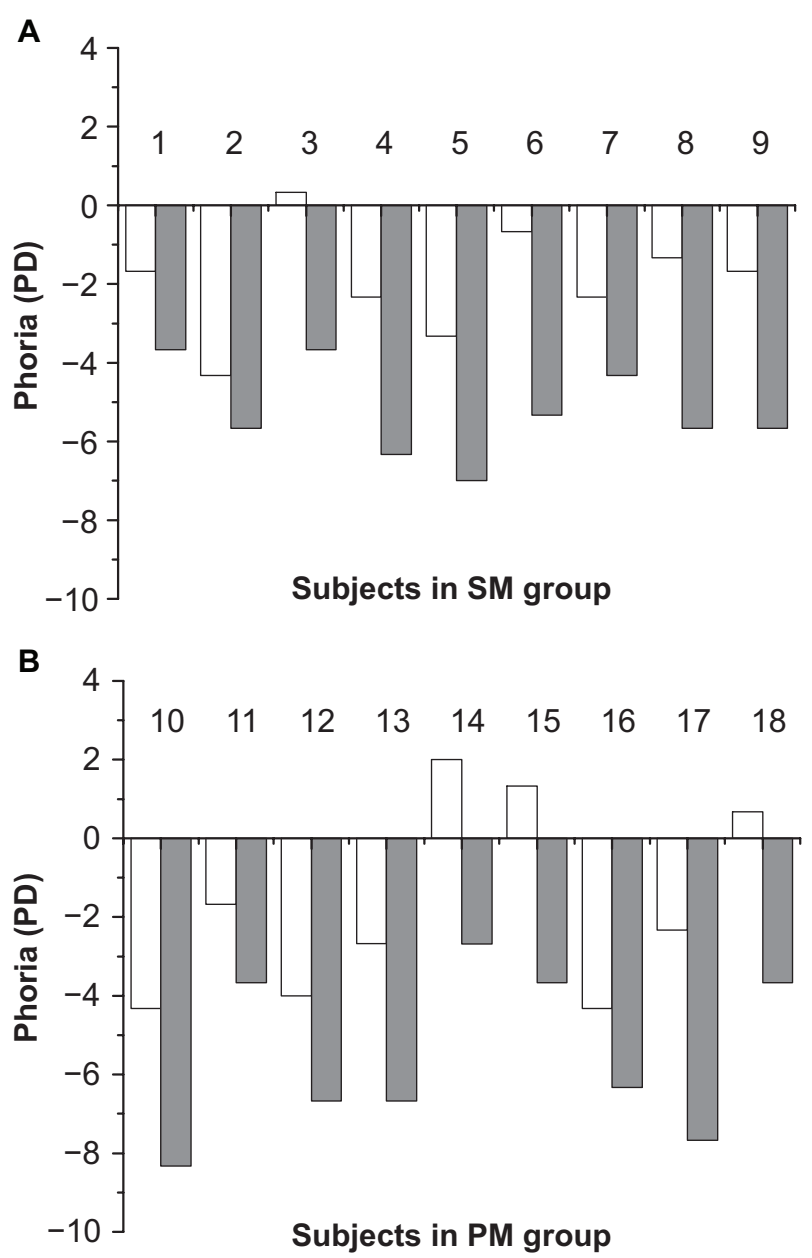

Figure 2 The initial near phoria (white bars) and the near phoria with C-ADD (dark bars) for each subject: A) subjects in the SM group; B) subjects in PM group. In the y-axis, + sign represents esophoria; - sign represents exophoria.

Abbreviations: C-ADD, customized near addition lenses; SM, stable myopia; PM, progressive myopia.

\section{Discussion}

In this study, we applied the results of a previous study ${ }^{39}$ to determine the best powers of near-addition lenses for nine SMs and nine PMs. With C-ADD, the AE for each subject was significantly reduced. As expected, the lenses also shifted the near phoria of the subject in the exo direction. However, the near phorias for most subjects were still in the normal range $(-3 \pm 3 \mathrm{pd}){ }^{44}$ The results of this study showed that the C-ADD reduced NITM significantly for subjects in the SM group. However, we did not find a significant effect of the C-ADD on NITM for individuals in the PM group. We speculate that a larger sample might help to find a significant effect for progressive myopes.

Clinicians and researchers have tried to use bifocal or PALs to control myopia progression in previous studies. However, the results of these investigations were not consistent. Investigations on accommodation and vergence performance with $+2 \mathrm{D}$ near-addition lenses found that the binocular dioptric value (the combination of a subject's AR and the power of near-addition lenses) tended to exceed the AS level and create myopic defocus during near vision. ${ }^{37,38}$ At the same time, the near phoria was usually shifted in the exophoric direction and was out of the normal range. A recent report by Sreenivasan et $\mathrm{a}^{45}$ studied the effect of binocular adaptation to $+2 \mathrm{D}$ near-additions on response $\mathrm{AC} / \mathrm{A}$ ratios of myopic and emmetropic children. Based on their results, they suggested that the +2 D near-additions would reduce both lag of accommodation and esophoria, and therefore may be beneficial for myopic children with near esophoria. However, such adds may not be helpful in myopes with a high exophoria because the reduced vergence adaptation leads to increased exophoria and increases the stress on the vergence system. This finding is consistent with results from a study by Gwiazda et al using +2 D near-addition lenses. ${ }^{36}$ Following on from the study by Jiang et $\mathrm{al}^{39}$ we calculated the powers of near-addition lenses based on the subject's initial AE and near phoria in order to get the smallest errors in accommodative and vergence responses. The calculated results from the two equations, one based on the initial $\mathrm{AE}$ and the other based on the initial near phoria, could be different for each subject. Therefore the average was taken in order to balance the accommodative error and vergence load for near visual work. The powers of C-ADD for the 18 subjects were within the range $0.50-2.00 \mathrm{D}$. The experimental results suggested that C-ADD effectively reduced retinal defocus, while retaining an appropriate vergence load when viewing a near target at $40 \mathrm{~cm}$. Cheng et al approached this problem in a slightly different way, ${ }^{46}$ using a lens combination of $+2.25 \mathrm{D}$ with a 6 pd base-in prism, and successfully reduced the accommodative error and phoria of myopic children. Because of the potential for prism adaptation, further work may be needed to verify whether the effect of this lens-prism combination will be maintained over time.

NITM is a transient near shift of the subject's far point after sustained near-work. ${ }^{21}$ The NITM is a phenomenon which reflects accommodative after effect/hysteresis after near adaptation..$^{47-49}$ This is related to a defect of sympathetic inhibition and instability of the crystalline lenses to reduce its power appropriately and rapidly. ${ }^{47,48}$ Myopes, especially PMs, tend to show greater magnitude and longer duration of NITM. ${ }^{24,50}$ During the period of NITM, the image on the retina is in a myopic defocus condition when the subject views a distance target. This is similar to the condition when myopia is undercorrected. Previous clinical observation ${ }^{51}$ and recent research ${ }^{52}$ showed that undercorrection of myopia could produce the development of myopia. The exact mechanism 


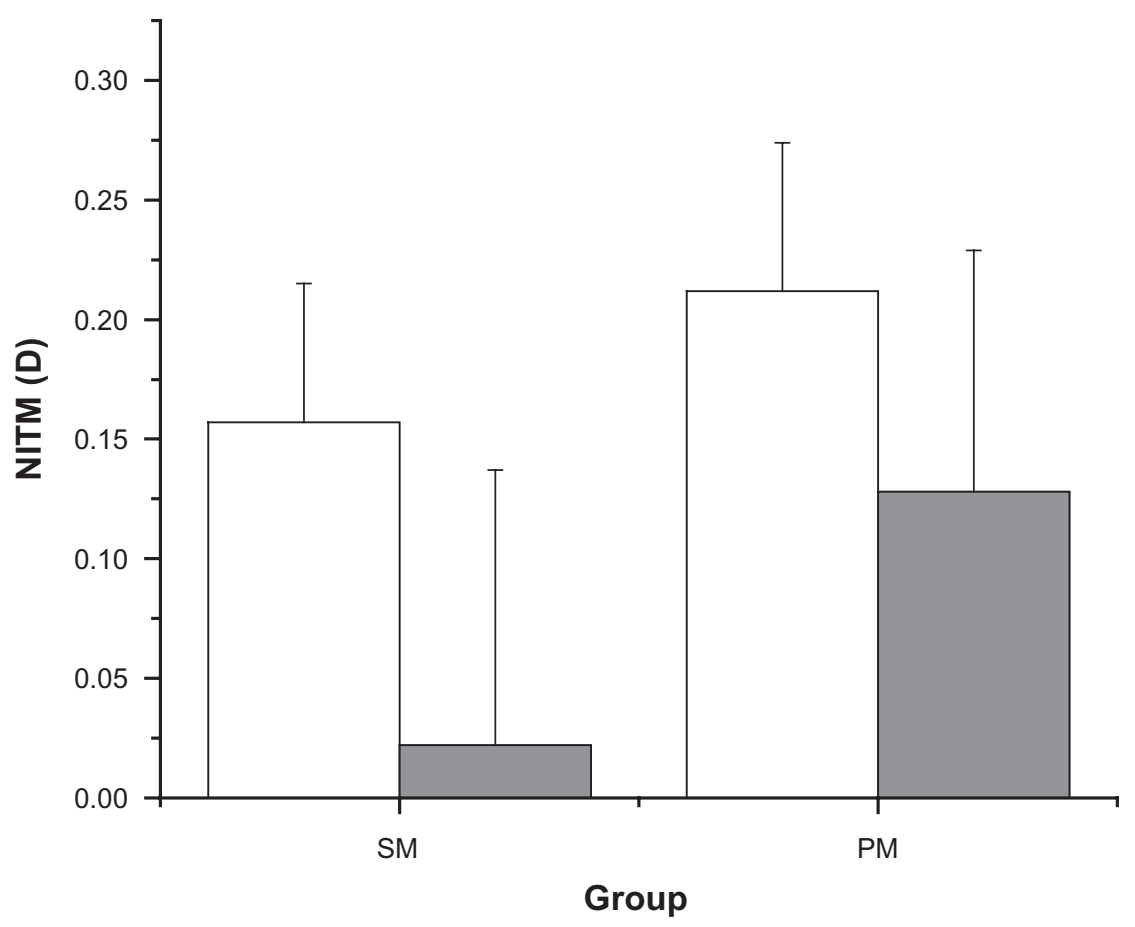

Figure 3 The NITM without (white bars) and with (dark bars) C-ADD averaged in SM and PM groups. Error bars represent \pm I SD.

Abbreviations: C-ADD customized near addition lenses; NITM, near-work induced transient myopia; SM stable myopia; PM progressive myopia.

of how the NITM caused axial elongation and permanent myopia development is not clear, but it has been speculated that it might be different from the results of animal studies, in that both myopic and hyperopic defocus in the retinal image can produce a myopic response in eye growth. ${ }^{26}$ Therefore, the NITM has been considered an indicator of development and progression of myopia. ${ }^{53,54}$ This study showed that the NITM change is significant $(P=0.0028)$ after the subjects used $\mathrm{C}$-ADD for the near visual task, although when we compare the difference in each refractive error group, the NITM change in the PM group is not significant. Further study on whether the effect of C-ADD on NITM could reduce the progression of myopia is warranted.

The C-ADD based on the subject's initial near AE and near phoria could decrease the defocus of the retinal image when viewing at near and the NITM after near-work. It also balances the accommodative and vergence loads, and might be a promising method to control the progression of myopia. While the subjects of this study were limited to young adults, the effectiveness of this method in children should be tested in future studies.

\section{Acknowledgement}

This study was supported by NSU HPD grant \#335249.

\section{Disclosures}

The authors report no conflict of interest in this work.

\section{References}

1. Kurtz D, Hyman L, Gwiazda JE, et al. The COMET Group. Role of parental myopia in the progression of myopia and its interaction with treatment in COMET children. Invest Ophthalmol Vis Sci. 2007;48: 562-570.

2. Young TL, Metlapally R, Shay AE. Complex trait genetics of refractive error. Arch Ophthalmol. 2007;125:38-48.

3. Hung GK, Ciuffreda KJ. Model of human refractive error development. Curr Eye Res. 1999;19:41-52.

4. Saw SM, Chua WH, Hong, et al. Nearwork in early-onset myopia. Invest Ophthalmol Vis Sci. 2002;43:332-339.

5. Ip JM, Saw SM, Rose KA, et al. Role of near-work in myopia: Findings in a sample of Australian school children. Invest Ophthalmol Vis Sci. 2008;49:2903-2910.

6. Saw SM, Tong L, Chua WH, et al. Incidence and progression of myopia in Singaporean school children. Invest Ophthalmol Vis Sci. 2005;46: 51-57.

7. Saw SM, Chua WH, Hong CY, et al. Nearwork in early-onset myopia. Invest Ophthalmol Vis Sci. 2002;43:332-339.

8. Jones LA, Sinnott LT, Mutti DO, Mitchell GL, Moeschberger ML, Zadnik K. Parental history of myopia, sports and outdoor activities, and future myopia. Invest Ophthalmol Vis Sci. 2007;48:3524-3532.

9. Mutti DO, Zadnik K. Has near work's star fallen? Optom Vis Sci. 2009;86:76-78.

10. Goss DA, Cox VD. Trends in the change of clinical refractive error in myopes. J Am Optom Assoc. 1985;56:608-613.

11. Bullimore MA, Reuter KS, Jones LA, Mitchell GL, Be JZ, Rah MJ. The study of progression of adult nearsightedness (SPAN): Design and baseline characteristics. Optom Vis Sci. 2006;83:594-604.

12. Goss DA, Wickham MG. Retinal-image mediated ocular growth as a mechanism for juvenile onset myopia and for emmetropization. A literature review. Doc Ophthalmol. 1995;90:341-375.

13. Siegwart JT, Norton TT. Regulation of the mechanical properties of tree shrew sclera by the visual environment. Vision Res. 1999;39:387-407.

14. Irving El, Callender MG, Sivak JG. Inducing myopia, hyperopia, and astigmatism in chicks. Optom Vis Sci. 1991;68:364-368. 
15. Gwiazda JE, Thorn F, Bauer J, Held R. Myopic children show insufficient accommodative response to blur. Invest Ophthalmol Vis Sci. 1993;34:690-694.

16. Abbott ML, Schmid KL, Strang NC. Differences in the accommodation stimulus response curves of adult myopes and emmetropes. Ophthal Physiol Opt. 1998;18:13-20.

17. Gwiazda J, Thorn F, Held R. Accommodation, accommodative convergence, and response $\mathrm{AC} / \mathrm{A}$ ratios before and at the onset of myopia in children. Optom Vis Sci. 2005;82:273-278.

18. Mutti DO, Mitchell GL, Hayes JR, et al. The CLEERE Study Group. Invest Ophthalmol Vis Sci. 2006;47:837-846.

19. Weizhong L, Zhikuan Y, Wen L, Xian C, Jian G. A longitudinal study on the relationship between myopia development and near accommodation lag in myopic children. Ophthal Physiol Opt. 2008;28:57-61.

20. McBrien NA, Adams DW. A longitudinal investigation of adult-onset and adult-progression of myopia in an occupational group. Invest Ophthalmol Vis Sci. 1997;38:321-333.

21. Ciuffreda KJ, Wallis DM. Myopes show increased susceptibility to nearwork after effects. Invest Ophthalmol Vis Sci. 1998;39:1797-1803.

22. Wolffsohn JS, Gilmartin B, Li RW, et al. Invest Ophthalmol Vis Sci. 2003;44:2284-2289.

23. Ciuffreda KJ, Vasudevan B. Nearwork-induced transient myopia (NITM) and permanent myopia - is there a link? Ophthalmol Physiol Opt. 2008;28:103-114.

24. Vasudevan B, Ciuffreda K. Additivity of near work-induced transient myopia and its decay characteristics in different refractive group. Invest Ophthalmol Vis Sci. 2008;49:839-841.

25. Ciuffreda KJ, Wallis DM. Myopes show increased susceptibility to nearwork aftereffects. Invest Ophthalmol Vis Sci. 1998;39:1797-1803.

26. Ciuffreda KJ, Lee M. Differential refractive susceptibility to sustained nearwork. Ophthalmic Physiol Opt. 2002;22:372-379.

27. Edwards MH, Li RW, Lam CS, Lew JK, Yu BS. The Hong Kong progressive lens myopia control study: Study design and main findings. Invest Ophthalmol Vis Sci. 2002;43:2852-2858.

28. Parssinen O, Hemminki E, Klemetti A. Effect of spectacle use and accommodation on myopic progression: Final results of a three-year randomized clinical trial among schoolchildren. $\mathrm{Br} J$ Ophthalmol. 1989;73:547-551.

29. Grosvenor T, Perrigin DM, Perringin J, Maslovits B. Houston myopia control study: A randomized clinical trial. Part II. Final reported by the patient care team. Am J Optom Physiol Opt. 1987;64:482-496.

30. Gwiazda J, Hyman L, Hussein M, et al. The COMET Group. A randomized clinical trial of progressive addition lenses versus single vision lenses on the progression of myopia in children. Invest Ophthalmol Vis Sci. 2003;44:1492-1500.

31. Leung JTM, Brown B. Progression of myopia in Hong Kong Chinese schoolchildren is slowed by wearing progressive lenses. Optom Vis Sci. 1999;76:346-354.

32. Goss DA, Rainey BB. Relationship of accommodative response and nearpoint phoria in a sample of myopic children. Optom Vis Sci. 1999; 76:292-294.

33. Goss DA. Effect of bifocal lenses on the rate of childhood myopia progression. Optom Vis Sci. 1986;63:135-141.

34. Fulk GW, Cyert LA, Parker DF. A randomized trial of the effect of single-vision vs. bifocal lenses on myopia progression in children with esophoria. Optom Vis Sci. 2000;77:395-401.
35. Brown B, Edwards MH, Leung JTM. Is esophoria a factor in slowing of myopia by progressive lenses? Optom Vis Sci. 2002;79:638-642.

36. Gwiazda JE, Hyman L, Norton TT, et al; The COMET Group. Accommodation and related risk factors associated with myopia progression and their interaction with treatment in COMET children. Invest Ophthalmol Vis Sci. 2004;45:2143-2151.

37. Rosenfield M, Carrel MF. Effect of near-vision addition lenses on the accuracy of the accommodative response. Optometry. 2001;72:19-24.

38. Jiang BC, Tea Y, O'Donnell D. Changes in accommodative and vergence responses when viewing through near addition lenses. Optometry. 2007;78:128-134.

39. Jiang BC, Bussa S, Tea Yin, Seger K. Optimal dioptric value of near addition lenses intended to slow myopic progression. Optom Vis Sci. 2008;85:1100-1105.

40. Jiang BC, Schatz S, Seger K. Myopic progression and dark focus variation in optometric students during the first academic year. Clin Exp Optom. 2005;88:153-159.

41. Salmon TO, West RW, Gasser W, Gasser W, Kenmore T. Measurement of refractive errors in young myopes using the COAS Shark-Hartmann aberrometer. Optom Vis Sci. 2003;80:6-14.

42. Salmon TO, van de Pol C. Evaluation of a clinical aberrometer for lower-order accuracy and repeatability, higher order repeatability, and instrument myopia. Optometry. 2005;76:461-472.

43. Martinez AA, Pandian A, Sankaridurg P, Rose K, Huynh SC. Mitchell P. Comparison of aberrometer and autorefractor measures of refractive error in children. Optom Vis Sci. 2006;83:811-817.

44. Scheiman M, Wick B. Clinical management of binocular vision. 1st ed. Philadelphia; Pennsylvania: JB Lippincott Co.,1994.

45. Sreenivasan V, Irving EL, Bobier WR. Binocular adaptation to $+2 \mathrm{D}$ lenses in myopic and emmetropic children. Optom Vis Sci. 2009;86: 731-740.

46. Cheng D, Schmid KL, Woo GC. The effect of positive-lens addition and base-in prism on accommodation accuracy and near horizontal phoria in Chinese myopic children. Ophthalmic Physiol Opt. 2008;28:225-237.

47. Ong E, Ciuffreda K. Nearwork-induced transient myopia a critical review. Doc Ophthalmol. 1995;91:57-85.

48. Vasudevan B, Ciuffreda KJ, Gilmartin B. Sympathetic inhibition of accommodation of following sustained nearwork in myopes and emmetropes. Invest Ophthalmol Vis Sci. 2009;50:114-120.

49. Gilmartin B, Bullimore MA, Rosenfield M, Winn B, Owens H. Pharmacological effects on accommodative adaptation. Optom Vis Sci. 1992;69:276-282.

50. Vera-Diaz FA, Strang NC, Winn B. Nearwork induced myopia during myopia progression. Curr Eye Res. 2002;24:289-295.

51. Goss DA. Attempts to reduce the rate of increase of myopia in young people - a critical literature review. Am J Optom Physiol Opt. 1982;59:828-841.

52. Chung K, Mohidin N, O'Leary DJ. Undercorrection of myopia enhances rather than inhibits myopia progression. Vision Res. 2002;42: $2555-2559$

53. Hung G, Cuiffreda KJ. A unifying theory of refractive error development. Bull Math Biol. 2000;62:1087-1108.

54. Hung G, Ciuffreda KJ. Incremental retinal-defocus theory of myopia development-schematic analysis and computer simulation. Comput Biol Med. 2007;37:930-946.
Clinical Optometry

\section{Publish your work in this journal}

Clinical Optometry is an international, peer-reviewed, open access journal publishing original research, basic science, clinical and epidemiological studies, reviews and evaluations on clinical optometry. All aspects of patient care are addressed within the journal as well as the practice of optometry including economic and business analyses. Basic and clinical Submit your manuscript here: http://www.dovepress.com/clinical-optometry-journal

\section{Dovepress}

research papers are published that cover all aspects of optics, refraction and its application to the theory and practice of optometry. The manuscript management system is completely online and includes a very quick and fair peer-review system, which is all easy to use. Visit http://www.dovepress. com/testimonials.php to read real quotes from published authors. 